\title{
Enhancement of combustion characteristics of VCR diesel engine by optimizing engine parameters
}

\author{
Prabhakara Rao Ganji $^{1}$ [D $\cdot$ Rajesh Khana Raju Vysyaraju ${ }^{2} \cdot$ Srinivasa Rao Surapaneni $^{2} \cdot$ B. Karuna Kumar ${ }^{1}$
}

Received: 13 March 2021 / Accepted: 15 July 2021

Published online: 30 July 2021

(c) The Author(s) 2021

OPEN

\begin{abstract}
In recent years, engine emissions have been one of the important problems which are of great concern. Hence, there is a growing need to develop engines with reduced emission. In the present study, Variable Compression Ratio diesel engine model has been validated by comparing the simulation results with the experimental. The study is aimed at analyzing the effect of compression ratio, exhaust gas recirculation, fuel injection pressure and start of injection on engine performance and emission characteristics. Using composite desirability technique, the engine parameters have been optimized to achieve lower NOx, soot and ISFC. The optimum combination has been observed at Compression ratio 17.52, Start of injection $-30.1^{\circ} \mathrm{aTDC}$, Fuel injection pressure 736.06 bar and Exhaust gas recirculation $28.29 \%$. ISFC, NOx and soot are reduced by $2.37 \%, 29.11 \%$ and $83.81 \%$ respectively. Higher Target Fuel Distribution Index indicates the improved mixture homogeneity for the optimized parameters.
\end{abstract}

Keywords Compression ratio · Exhaust gas recirculation · Fuel injection pressure · Start of injection

\section{Introduction}

Emission control has been a major challenge faced by the modern world. IC engine being a major source of emission have to be optimized in order to improve combustion and reduce emission. In addition, diesel engines have proved to be a great threat to the environment compared to $\mathrm{SI}$ engines in consideration to their high NOx and soot emission. Hence, diesel engines must be designed in order to improve their performance. These days the use of catalytic converters has come into existence. However, these are expensive. Designing an engine without incorporating any such components would be a cost effective approach [5, 16-18, 23, 26, 31].

Experimental work carried out by [1] explains the effect of EGR on performance, emission and carbon deposits in a diesel engine. It explains how the EGR displace oxygen in the intake air and reduces the oxygen content in the combustion chamber. The specific heat of the intake air mixture increases which reduces the flame temperature. This also reduces the specific fuel consumption. In a nutshell, EGR is an effective method that can be applied to a diesel engine to reduce NOx emission without sacrificing its fuel economy and efficiency. Min et al. [20] studied the effect of EGR by changing the $\mathrm{N}_{2}$ mass fraction results show that the indicated specific NOx emissions were decreased with increased EGR fractions while increases soot emissions. The simultaneous reduction of NOx and soot was done by optimizing the engine parameters.

Jayashankara and Ganesan [14] worked on diesel engine to study the effect of fuel injection timing and injection pressure on its performance. Advanced injection

Prabhakara Rao Ganji, ganjiprabhakar@gmail.com | ${ }^{1}$ Department of Mechanical Engineering, Gudlavalleru Engineering College, Gudlavalleru, Andhra Pradesh 521356, India. ${ }^{2}$ Department of Mechanical Engineering, National Institute of Technology, Warangal 506004, India. 
timing resulted in an increase in in-cylinder temperature, pressure, heat release rate and NOx emissions. Advancing the injection timing increased the soot while retarding the injection timing reduced the soot emission. But at high fuel injection pressures (1.7-2 bar) advancing the injection timing reduced the soot emission. According to the work of [28] the increase in fuel injection pressure reduced the specific fuel consumption and specific energy consumption whereas decrease in injection pressure increased fuel consumption per power output.

Song et al. [30] investigated on the effect of compression ratio on combustion characteristics for homogeneous charged compression ignition engine. It was observed that compression temperature and pressure in the cylinder vary significantly with compression ratio. The study concluded almost zero NOx emission at compression ratios 10.7 and 14. Prasad et al. [24] investigated that increasing compression ratio helps in improving efficiency and reduces soot where as NOx emissions increased. The effect of FIP (Fuel Injection Pressure) on the combustion and emission characteristics was not monotonic and there exists an optimum value of fuel injection pressure. Various studies have also been reported by using preheated alternative fuels blend with various oxide nano particles in the works of Elumalai $[9,11])$. It was found that inherent oxygen content improved its combustion characteristics.

From the literature it can be ascertained that improvement in the mixture homogeneity can be achieved by improvising the air-fuel mixing rate. The parameters such as EGR, compression ratio, SOI, injection pressure, etc. have shown a significant effect on air-fuel mixing rate. This can be done by optimizing the engine parameters such as

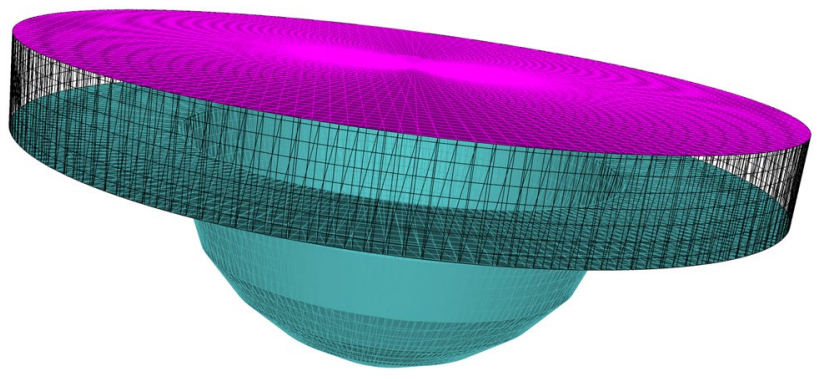

Fig. 1 Computational domain of variable compression ratio (VCR) engine model

\section{Computational domain and methodology}

CONVERGE ${ }^{\mathrm{TM}}$ [27] has been used for modeling the axi-symmetric engine sector and for simulation purpose. The computational domain of the VCR engine is shown in Fig. 1. The fluid flow properties are governed by the following equations:

Conservation of mass

$\frac{\partial \rho}{\partial \mathrm{t}}+\frac{\partial \rho u_{i}}{\partial x_{i}}=S i$

Conservation of momentum

$\frac{\partial \rho u_{i}}{\partial t}+\frac{\partial \rho u_{i} u_{j}}{\partial x_{j}}=-\frac{\partial P}{\partial x_{i}}+\frac{\partial \sigma_{i j}}{\partial x_{j}}+S i$

Conservation ofenergy

$\frac{\partial \rho}{\partial \mathbf{t}}+\frac{\partial \mathbf{u}_{\mathbf{j}} \rho \mathbf{e}}{\partial \mathbf{x}_{\mathbf{j}}}=-\mathbf{p} \frac{\partial \mathbf{u}_{\mathbf{j}}}{\partial \mathbf{x}_{\mathbf{j}}}+\boldsymbol{\sigma} \mathbf{i j} \frac{\partial \mathbf{x}_{\mathbf{i}}}{\partial \mathbf{x}_{\mathbf{j}}}+\frac{\partial}{\partial \mathbf{x}_{\mathbf{j}}} \mathbf{K}\left(\frac{\partial \mathbf{T}}{\partial \mathbf{x}_{\mathbf{j}}}\right)+\frac{\partial}{\partial \mathbf{x}_{\mathbf{j}}}\left(\rho \mathbf{D} \sum_{\mathbf{m}} \mathbf{h}_{\mathbf{m}} \frac{\partial \mathbf{Y}_{\mathbf{m}}}{\partial \mathbf{x}_{\mathbf{j}}}\right)+\mathbf{S i}$

fuel injection pressure, compression ratio, injection timing, EGR, etc.[4].

The primary objective of this work is to improve the mixture homogeneity and analyze the effects of various parameters and their interactions on the ISFC, NOx, and soot. The simulations were performed based on design of experiments (DOE) using response surface methodology. The work also aims to find the optimal combination of compression ratio, exhaust gas recirculation, fuel injection pressure, and start of injection, which would result in better performance with reduced NOx, soot emissions.
Equation of state presented below is used to couple density, temperature and pressure

$\frac{\mathrm{P}}{\rho}=\mathrm{Z}\left[\frac{\mathrm{R}}{\mathrm{W}}\right]$

Optimization of engine parameters has been done using Design of Experiments (DOE) method. This method is effective in optimizing the engine parameters by evaluating the combined effect of input factors on output responses. The DOE technique considered in the present study is Response Surface Methodology (RSM). RSM is an efficient way of reducing the computational time with reasonable accuracy. The main aim of RSM is optimizing an output response which is effected by various input factors $[6,22]$. 
The following 2 nd order polynomial equation represents a simple approximating function

$y=\beta_{0}+\sum_{i=1}^{n} \beta_{i} x_{i}+\sum_{i=1}^{n} \beta_{i i} x_{i}^{2}+\sum_{1 \leq i \leq j}^{n} \beta_{i j} x_{i} x_{j}+\varepsilon$

where, ' $n$ ' denotes the number of variables, $\beta_{0}$ denotes the constant term, $\beta_{i}$ denotes the coefficient of linear terms, $\beta_{i j}$ denotes the coefficient of interaction terms and $\varepsilon$ denotes the error.

\section{Validation of VCR engine model (Diesel)}

The simulation and experimental results are compared to validate numerical results obtained for VCR diesel case from CFD code CONVERGE ${ }^{\mathrm{TM}}$. The VCR engine specifications are given in Table 1. Validation of the predicted numerical results with that of the experimental data was carried out by comparing the pressure variation with crank angle. Figure 2 shows the variation of pressure with crank angle for experimental and simulation results. The trends of simulation are similar to that of experiment. However, a slight difference of around $1.2 \%$ in peak pressure is observed. Experimental pressure shows lesser as compared to simulation. This may be due the fact that during the compression stroke the gases may escape from the crevice region and would end up with lower in-cylinder pressure. This shows that the present model is in good accordance with the experimental results of the VCR diesel engine.

Table 1 Specifications of VCR engine

\begin{tabular}{ll}
\hline Cylinder bore $\times$ stroke $(\mathrm{mm})$ & $87.5 \times 110 \mathrm{~mm}$ \\
\hline Connecting rod length $(\mathrm{mm})$ & $234 \mathrm{~mm}$ \\
Displacement volume $(\mathrm{L})$ & 0.66 \\
Compression ratio & 17.5 \\
Number of nozzle orifice $\times$ diameter & $3 \times 0.255$ \\
$\quad(\mathrm{~mm})$ & \\
Piston crown & Hemispherical \\
Intake valve closure (CA) & $144.5^{\circ} \mathrm{bTDC}$ \\
Swirl ratio (nominal) & 0.7 \\
Inlet air temperature (K) & 303 \\
Inlet air pressure $(\mathrm{kPa})$ & 111 \\
Engine speed (rpm) & $1500 \mathrm{rpm}$ \\
Fuel & Diesel/PB20 \\
Type of fuel injection & Direct Injection \\
Injection pressure $(\mathrm{MPa})$ & 28 \\
Fuel injected (kg/cycle) & $2.57778 \mathrm{e}-05$ \\
Overall equivalence ratio & 0.55 \\
Injection duration & $21 \mathrm{crank}$ angle degrees \\
Start of injection & $23^{\circ} \mathrm{bTDC}$ (baseline case) \\
\hline
\end{tabular}

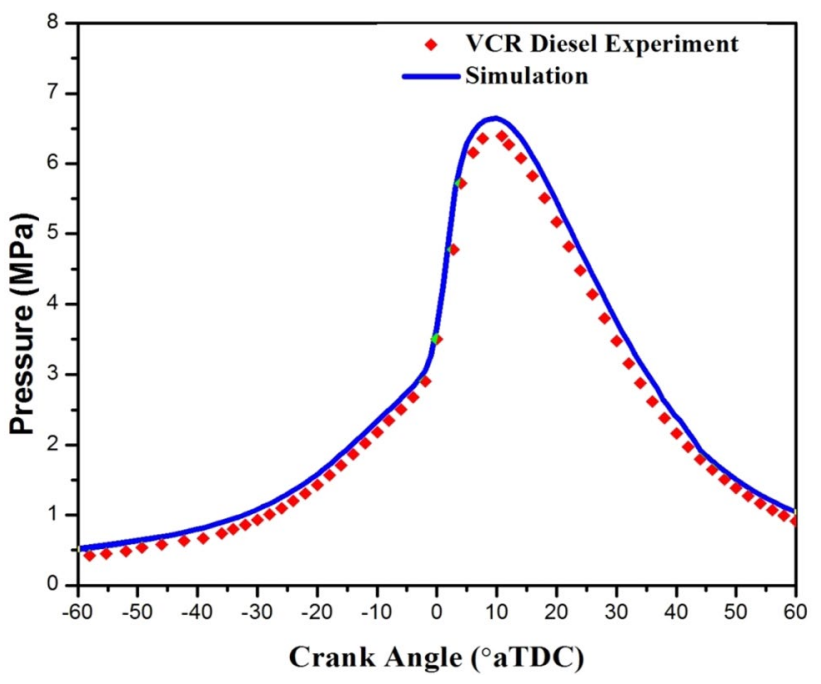

Fig. 2 Validation of pressure versus Crank Angle for VCR diesel engine

Validation of emissions were also performed by comparing the experimental soot and NOx emissions with the simulation values and given in Table 2 . It is observed that they are in good harmony.

\section{Results and discussions}

Box-Behnken method was applied for designing the numerical experiments. In this method each variable is maintained at 3 equal intervals. For example, if the $C R$ range is from 12 to 18 , it is assigned as 12,15 and 18 and considered for numerical experiment design. Since there are 4 variables and 3 center points, it becomes a set of 27 experiments with each block having 2 variations (means two independent variables are varied per experiment). The design of experiments and their responses are given the Table 3.

\subsection{Interaction effects of VCR Diesel engine}

The interactive effect graphs are generated through modeFrontier [12] software. Figure 3 shows the interaction plots of EGR and CR at different levels of SOI and FIP VCR diesel engine. It can be observed from figure that in the interaction of EGR and $C R$, as the EGR is increased from 0

Table 2 Validation of emission analysis

\begin{tabular}{lll}
\hline Emissions & Experimental & Simulation \\
\hline NOx $(\mathrm{g} / \mathrm{kWh})$ & 4.98 & 5.29 \\
Soot $(\mathrm{g} / \mathrm{kWh})$ & 1.15 & 1.18 \\
\hline
\end{tabular}


Table 3 Experimental design and their responses for VCR diesel engine

\begin{tabular}{|c|c|c|c|c|c|c|c|}
\hline Run order & $C R$ & SOI ('bTDC) & FIP (bar) & EGR (\%) & ISFC (g/kWh) & Soot (g/kWh) & $\mathrm{NO}_{\mathrm{x}}(\mathrm{g} / \mathrm{kWh})$ \\
\hline 1 & 18 & 27.5 & 250 & 20 & 242.811 & 0.48552 & 4.15 \\
\hline 2 & 18 & 27.5 & 625 & 0 & 195.396 & 0.04004 & 10.4732 \\
\hline 3 & 15 & 40 & 625 & 0 & 182.571 & 0.78328 & 12.1134 \\
\hline 4 & 15 & 27.5 & 625 & 20 & 226.281 & 0.61038 & 2.97377 \\
\hline 5 & 18 & 27.5 & 1000 & 20 & 217.721 & 0.11951 & 5.03205 \\
\hline 6 & 15 & 27.5 & 1000 & 0 & 208.337 & 0.64078 & 8.47935 \\
\hline 7 & 18 & 40 & 625 & 20 & 195.497 & 0.10355 & 8.547 \\
\hline 8 & 12 & 27.5 & 625 & 40 & 261.431 & 1.216 & 1.45875 \\
\hline 9 & 15 & 27.5 & 250 & 0 & 237.53 & 0.74746 & 6.234 \\
\hline 10 & 12 & 15 & 625 & 20 & 264.755 & 1.64901 & 0.5319 \\
\hline 11 & 15 & 40 & 625 & 40 & 210.29 & 0.92654 & 3.897 \\
\hline 12 & 12 & 27.5 & 250 & 20 & 277.856 & 1.22303 & 1.12884 \\
\hline 13 & 15 & 27.5 & 1000 & 40 & 232.921 & 0.70414 & 1.48125 \\
\hline 14 & 15 & 15 & 250 & 20 & 277.571 & 2.01875 & 0.9867 \\
\hline 15 & 12 & 27.5 & 1000 & 20 & 256.956 & 0.5529 & 2.03835 \\
\hline 16 & 12 & 40 & 625 & 20 & 218.643 & 0.9291 & 5.9634 \\
\hline 17 & 15 & 15 & 1000 & 20 & 227.193 & 1.3965 & 1.5768 \\
\hline 18 & 15 & 27.5 & 625 & 20 & 221.707 & 0.61038 & 2.8035 \\
\hline 19 & 15 & 15 & 625 & 0 & 223.25 & 1.292 & 6.23505 \\
\hline 20 & 15 & 40 & 1000 & 20 & 209.171 & 0.93376 & 7.1258 \\
\hline 21 & 18 & 27.5 & 625 & 40 & 216.781 & 0.417 & 3.125 \\
\hline 22 & 18 & 15 & 625 & 20 & 214.596 & 1.32316 & 3.20124 \\
\hline 23 & 15 & 27.5 & 625 & 20 & 221.707 & 0.59442 & 2.73675 \\
\hline 24 & 15 & 40 & 250 & 20 & 231.306 & 1.0526 & 5.3205 \\
\hline 25 & 15 & 27.5 & 250 & 40 & 257.132 & 1.7005 & 0.67695 \\
\hline 26 & 12 & 27.5 & 625 & 0 & 224.184 & 0.70167 & 5.125 \\
\hline 27 & 15 & 15 & 625 & 40 & 237.747 & 2.11351 & 1.9125 \\
\hline
\end{tabular}

to $40 \%$ ISFC increased from the level 195 to $265 \mathrm{~g} / \mathrm{kWh}$. It is observed from the figure that the ISFC is favorable in the mid to high range of FIP and SOI. The operating range of CR between high and mid (fig (a), (b) and (d)) seems to be quite favorable in reducing ISFC. Further, a detailed view can reveal that operating range was good enough in the case of high FIP and mid SOI.

Figure 4 represents the interaction of CR and FIP on NOx emissions at different levels of EGR and SOI. It is observed from the figure that the NOx emissions are favorable in mid to high range of EGR and low to mid-range of SOI. It can also be interpreted from the figure that the increase in the fuel injection pressure increases NOx emissions [19]. Low EGR and high SOI combination is not fruitful at any stage of the interaction of CR and FIP. The effect of fuel injection pressure and compression ratio on NOx emissions mainly depends on the state of the mixture and ignition delay [29]. As the EGR is increased, the NOx decreases. This is due to the fact that EGR increases the specific heat of intake mixture, thus reduces the combustion temperature. It may also lower the amount of oxygen in the intake mixtures.
This combination of reduced combustion temperatures and reduced oxygen content lowers the NOx emissions.

Figure 5 shows contour plots of soot for SOI and CR at different levels of FIP and EGR. It is seen from the figure that the interaction of $\mathrm{CR}$ and $\mathrm{SOI}$ is dominant in the region of high EGR and mid to high FIP. The variation of interaction is less aggressive in the low EGR range. The interaction causes more fruitful region when the other two parameters (EGR and FIP) are set at low and high levels respectively $[2,15]$.

It is observed from the Table 4 that the difference between predicted and adjusted $R^{2}$ values is less than 0.2 for all the three responses, which implies that the model was able to fit the data with reasonably good accuracy. Analysis of variance (ANOVA) is used to determine the significant and insignificant parameters and their interactions. ANOVA gives the $p$ value for the different response parameters, such as ISFC, NOx, and soot emissions, and are given in Table 5. All the individual parameters (CR, SOI, FIP, and EGR) are significant for ISFC, NOx, and soot [13]. 


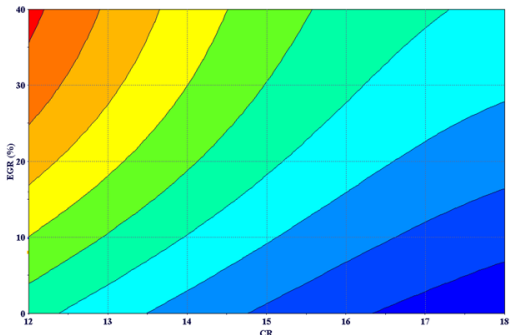

(a) HIGH FIP HIGH SOI

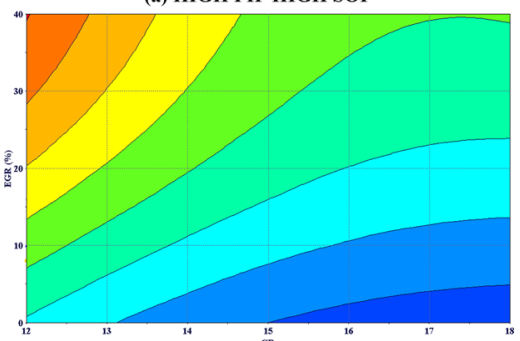

(d) MID FIP HIGH SOI

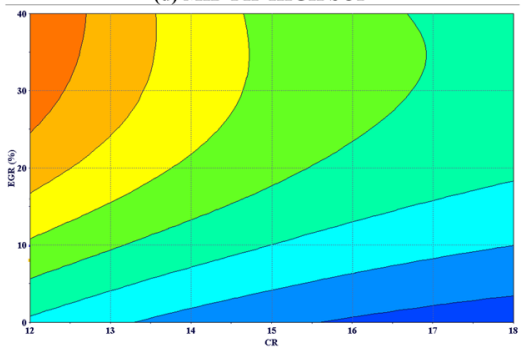

(g) LOW FIP HIGH SOI

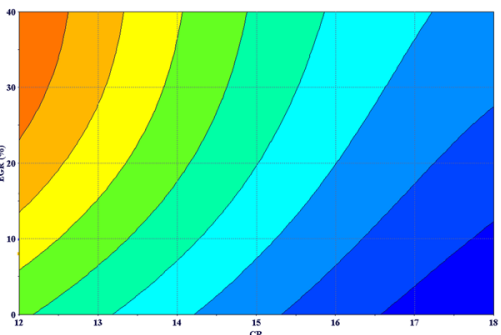

(b) HIGH FIP MID SOI

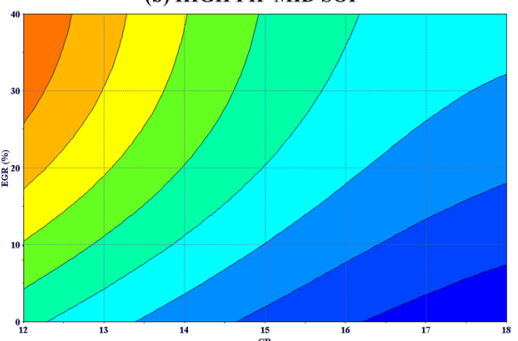

(e) MID FIP MID SOI

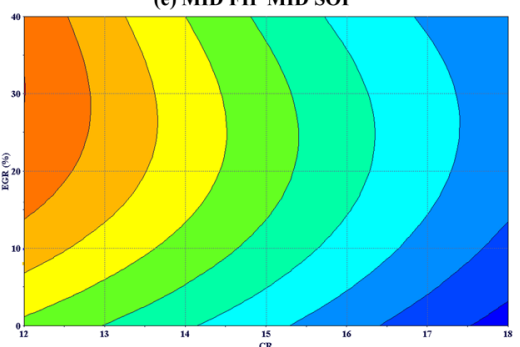

(h) LOW FIP MID SOI

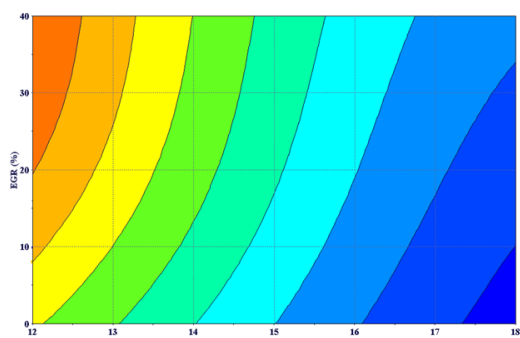

(c) HIGH FIP LOW SOI

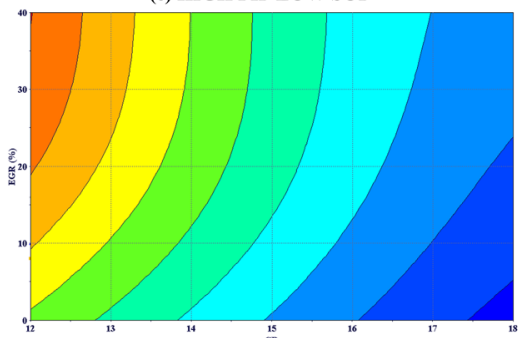

(f) MID FIP LOW SOI

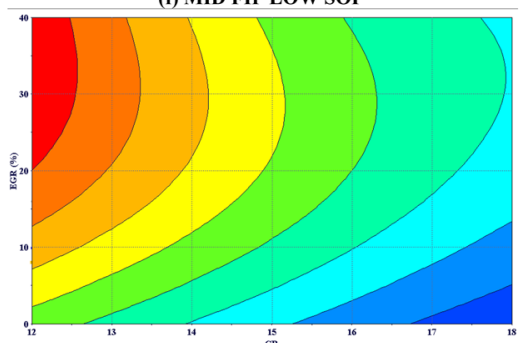

(i) LOW FIP LOW SOI

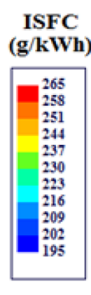

Fig. 3 Contour plots of ISFC for EGR and CR at different levels of SOI and FIP (VCR DIESEL)

\subsection{Optimization of VCR diesel}

The objective of any engine design is to minimize emissions and maximize the performance. It can be observed from the above discussions that the tradeoff is observed between the NOx and soot emissions. So there is a need for optimization of the design parameters aimed to reduce both NOx and soot without losing its performance. Optimization was performed using the desirability approach which is search based optimization technique $[6,7]$. The whole approach is to modify all the responses $\left(X_{i}\right)$ as a separate desirability function $\left(D_{i}\right)$ and then will be varied in the entire range.

$0 \leq\left(D_{i}\right) \leq 1$

If the response is at its mark value or objective, then $(D i)=1$ on the other hand, if the mark value is in the infeasible region then the $\left(D_{i}\right)=0$ [21]. Each of the desirability function is established depending upon the goal of optimization. Table 6 shows the criteria of optimization in the desirability approach. 


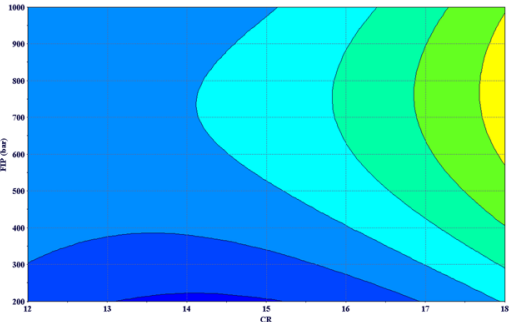

(a) HIGH EGR HIGH SOI

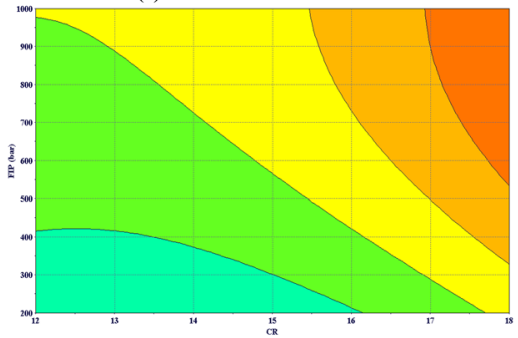

(d) MID EGR HIGH SOI

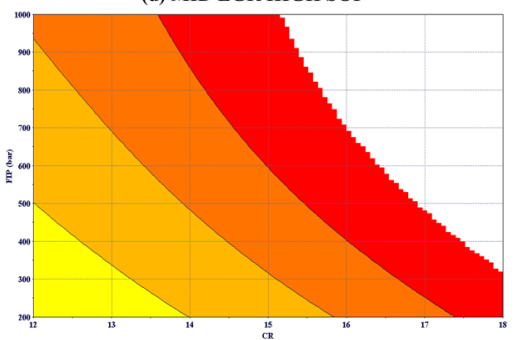

(g) LOW EGR HIGH SOI

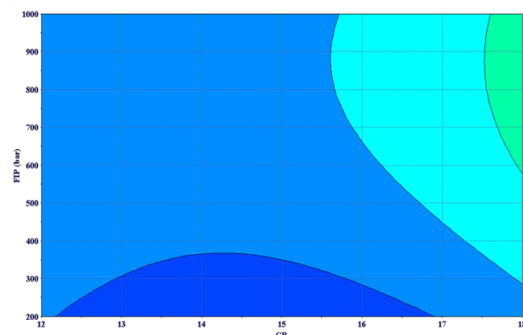

(b) HIGH EGR MID SOI

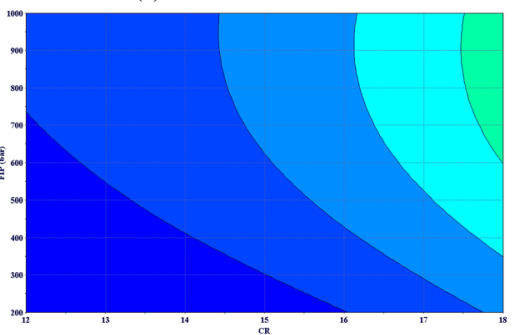

(e) MID EGR MID SOI

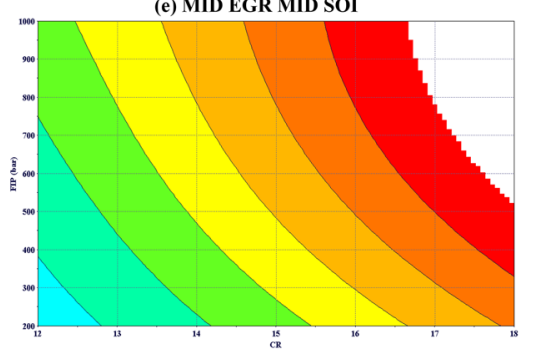

(h) LOW EGR MID SOI

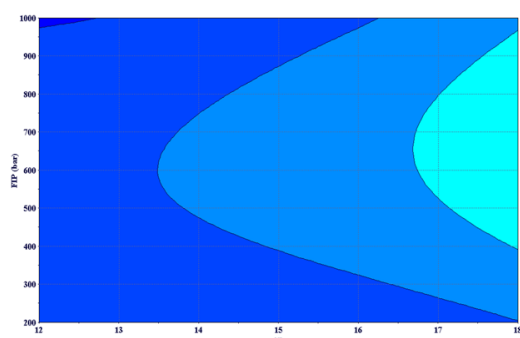

(c) HIGH EGR LOW SOI

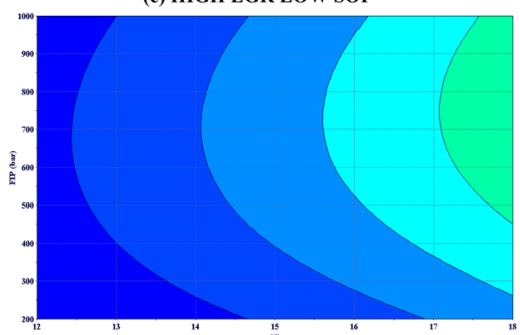

(f) MID EGR LOW SOI

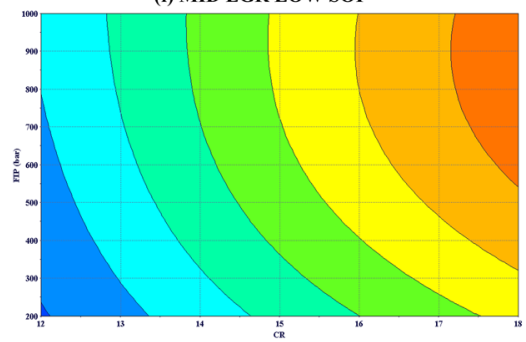

(i) LOW EGR LOW SOI
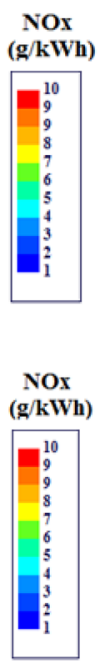

NOx $(\mathrm{g} / \mathrm{kWh})$

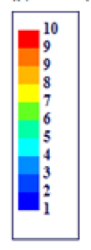

Fig. 4 Contour plots of NOx for FIP and CR at different levels of SOI and EGR (VCR DIESEL)

$D_{i}=\left\{\begin{array}{c}1 X_{i}<T_{i} \\ \left(\frac{U_{i}-X_{i}}{U_{i}-T_{i}}\right) T_{i} \leq X_{i} \leq U_{i} \\ 0 X_{i}>U_{i}\end{array}\right.$

where $U_{i}$ is the upper limit of the responses $\left(X_{i}\right), T_{i}$ is the target of the response.

The optimum combination of the VCR diesel case was found out to be the $17.52 \mathrm{CR}, 30.1^{\circ} \mathrm{bTDC}$ SOI, FIP $736.06 \mathrm{bar}$ and EGR $28.29 \%$ with a composite desirability of 0.95 .The compression ratio did not alter much from the baseline case which is also beneficial in terms of the design aspect.

\subsection{Comparison of optimized and baseline configuration of VCR (Diesel)}

The optimized and baseline cases of the VCR diesel engine were compared for pressure, temperature, NOx, soot, $\mathrm{HC}$ and $\mathrm{CO}$ vs crankangle and are shown in the Figs. 6, 7, 8, 9, 10 and 11 respectively. It was noticed from the Fig. 6 that the optimized case is superior in performance as the peak pressure of optimized is more as compared to the baseline case this is also manifested in Table 7 with reduced ISFC for optimized case. It is noticed from the Fig. 7 that the average temperature of the optimized case reduces during the combustion. This is because of the presence of EGR which could suppress the combustion temperature [8]. Figures 8 and 9 shows comparision of the NOx and soot formation for the optimised and baseline cases. It is evident that the both NOx and soot levels were deceased for the optimized case. It is also observed from Figs. 10 and 11 that the $\mathrm{HC}$ and $\mathrm{CO}$ emissions are decreased in the optimum case than the baseline. Table 7 gives the comparison of baseline and optimized cases of VCR diesel based on performance and emissions. It is noticed that the ISFC decreased by $2.37 \%$ 


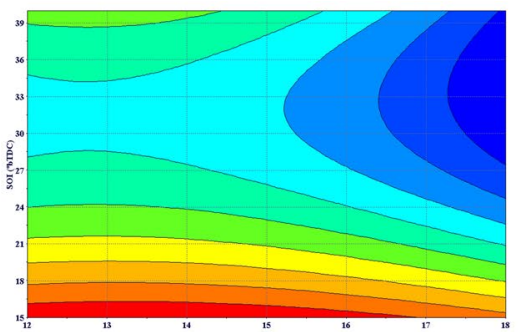

(a) HIGH EGR HIGH FIP

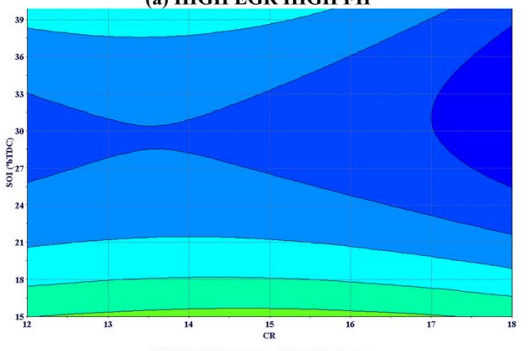

(d) MID EGR HIGH FIP

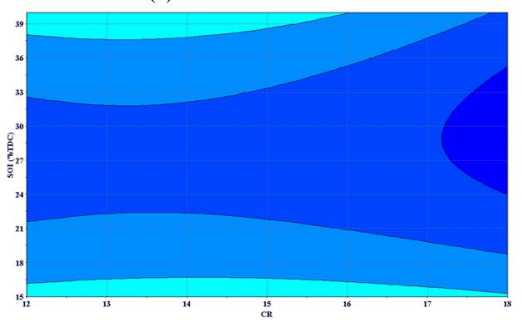

(g) LOW EGR HIGH FIP

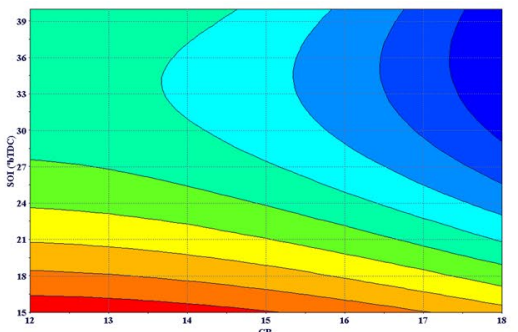

(b) HIGH EGR MID FIP

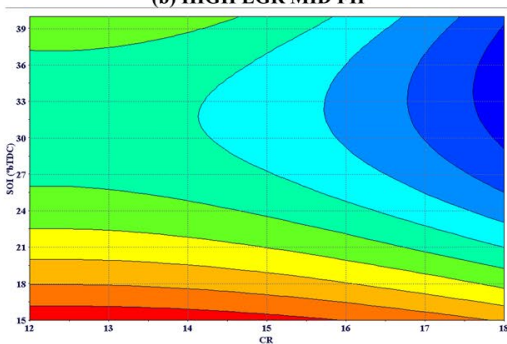

(e) MID EGR MID FIP

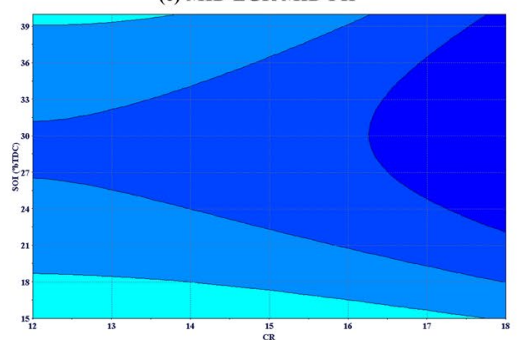

(h) LOW EGR MID FIP

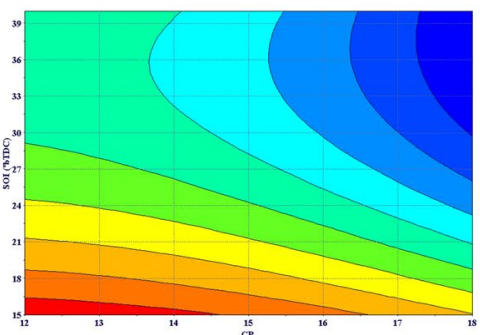

(c) HIGH EGR LOW FIP

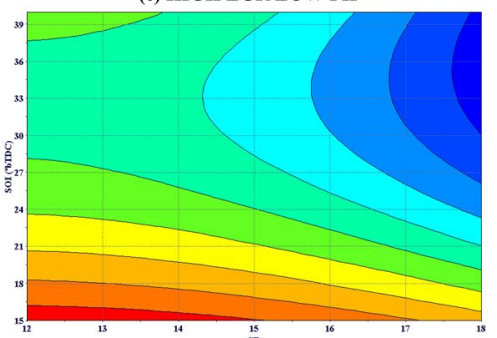

(f) MID EGR LOW FIP

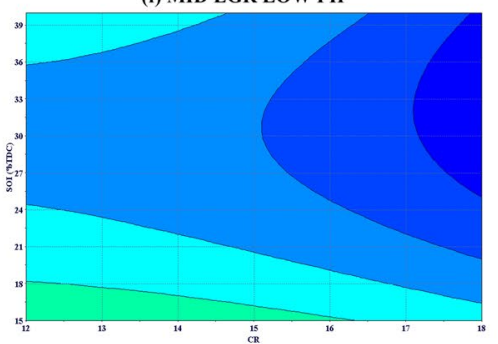

(i) LOW EGR LOW FIP
Soot

(g/kWh)

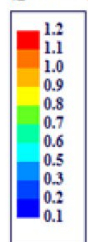

Soot (g/kWh)

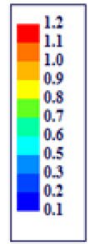

Soot (g/kWh)

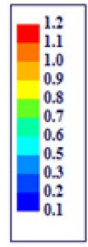

Fig. 5 Contour plots of soot for SOI and CR at different levels of FIP and EGR (VCR DIESEL)

Table 4 Model evaluation of RSM

\begin{tabular}{llll}
\hline & ISFC (g/kWh) & NOx (g/kWh) & Soot (g/kWh) \\
\hline R-sq & $99.93 \%$ & $97.91 \%$ & $99.14 \%$ \\
R-sq(adj) & $99.85 \%$ & $95.47 \%$ & $98.14 \%$ \\
R-sq(pred) & $99.61 \%$ & $87.96 \%$ & $95.06 \%$ \\
\hline
\end{tabular}

Table $5 p$ values for model terms of ANOVA analysis

\begin{tabular}{lccc}
\hline Source & ISFC & NOx & Soot \\
\hline CR & $<0.0001$ & $<0.0001$ & $<0.0001$ \\
SOI & $<0.0001$ & $<0.0001$ & $<0.0001$ \\
FIP & $<0.0001$ & $<0.0001$ & $<0.0001$ \\
EGR & $<0.0001$ & $<0.0001$ & $<0.0001$ \\
CR*SOI & $<0.0001$ & 0.477 & 0.006 \\
CR*FIP & $<0.0001$ & 0.011 & 0.065 \\
CR*EGR & 0.021 & 0.006 & 0.039 \\
SOI*FIP & $<0.0001$ & 0.020 & 0.006 \\
SOI*EGR & 0.121 & $<0.0001$ & 0.001 \\
FIP*EGR & $<0.0001$ & 0.039 & 0.000 \\
\hline
\end{tabular}

Table 6 Criteria of optimization used for desirability method for VCR diesel case

\begin{tabular}{lllll}
\hline Parameter/response & \multicolumn{2}{l}{ Limits } & \multicolumn{3}{c}{ Criterion } & Desirability \\
\cline { 2 - 3 } & Lower & Upper & & \\
\hline $\begin{array}{l}\text { Compression ratio } \\
\text { Fuel injection pressure }\end{array}$ & 12 & 18 & In range & 1 \\
$\quad$ (bar) & & 1000 & In range & 1 \\
Start of injection ('bTDC) & 15 & 40 & In range & 1 \\
$\begin{array}{l}\text { Exhaust gas recirculation } \\
\quad(\%)\end{array}$ & 0 & 40 & In range & 1 \\
ISFC (g/kWh) & 182.57 & 277.87 & Minimize & 0.98 \\
NOx (g/kWh) & 0.5 & 12.17 & Minimize & 0.84 \\
Soot (g/kWh) & 0.04 & 2.11 & Minimize & 0.99 \\
Combined & & & & 0.95
\end{tabular}




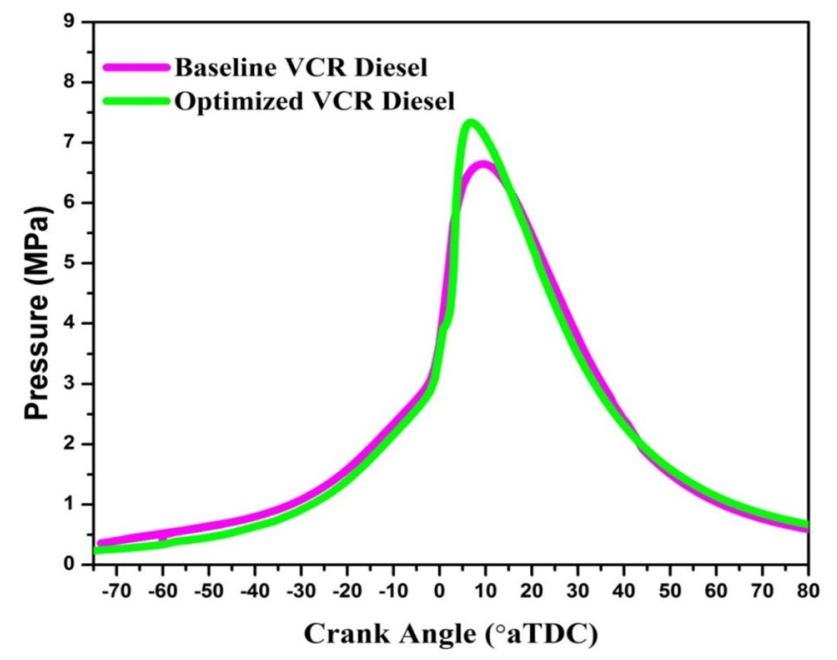

Fig. 6 Comparison of Pressure versus Crank Angle for optimized and baseline (VCR diesel)

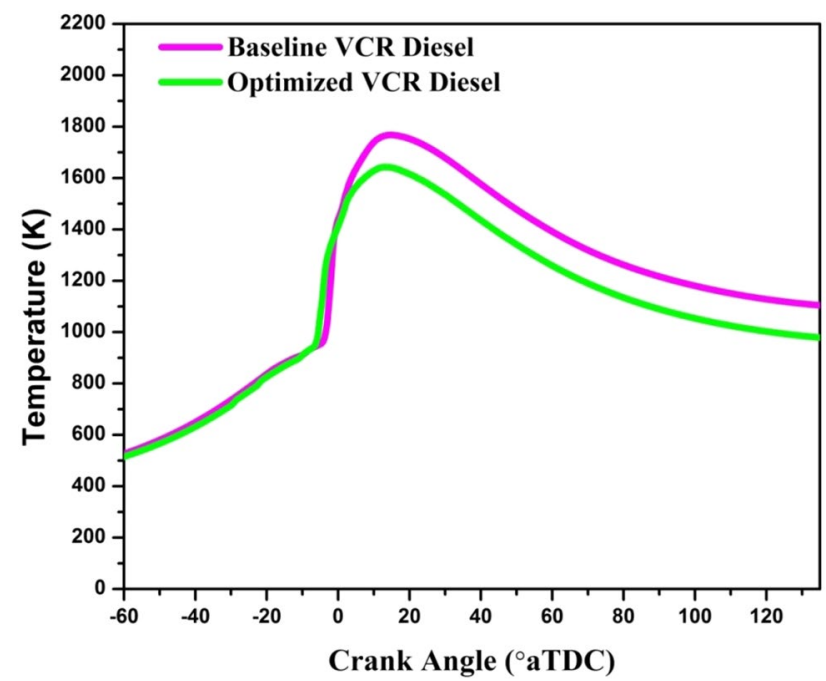

Fig. 7 Comparison of Temperature versus Crank Angle for baseline and optimized (VCR diesel)

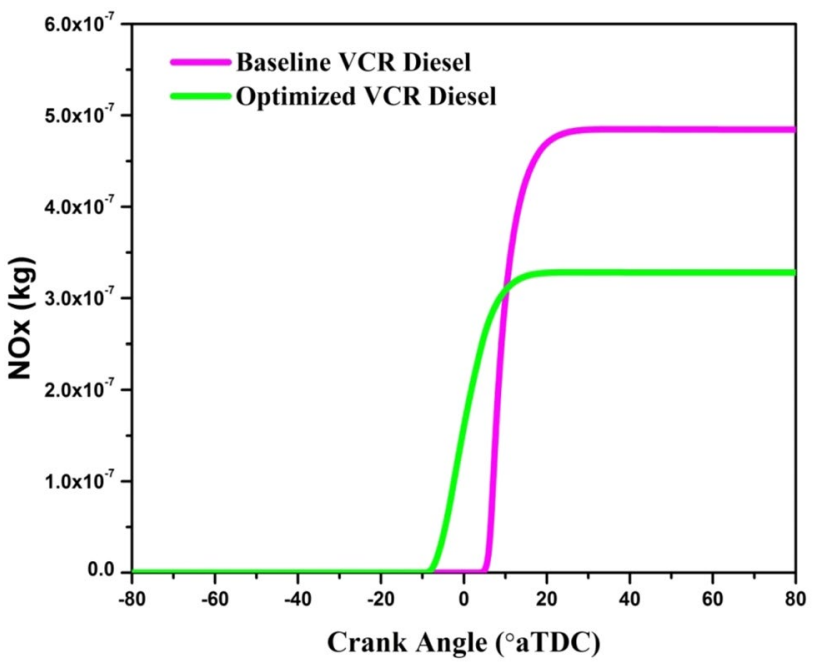

Fig. 8 Comparison of NOx versus Crank Angle for optimized and baseline (VCR diesel)

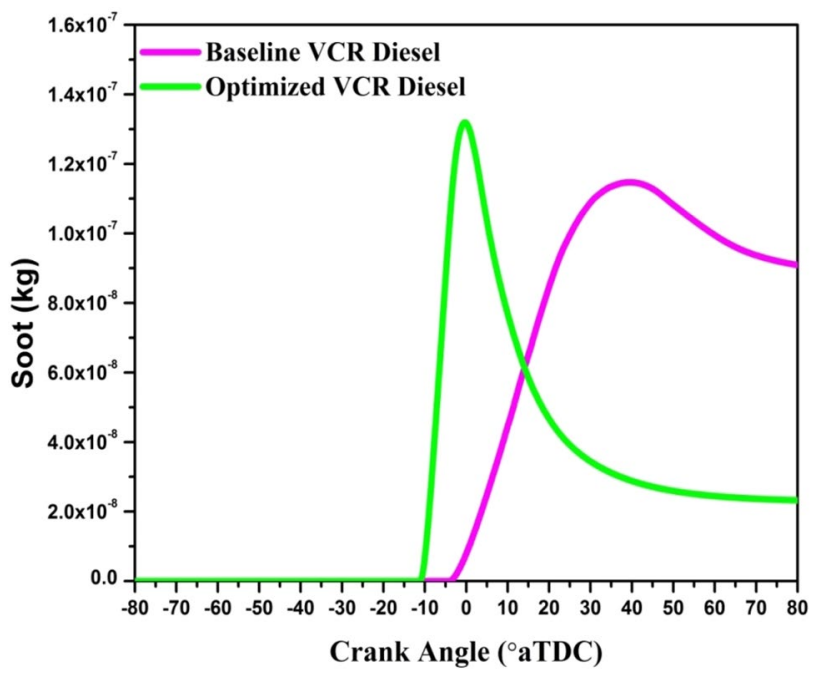

Fig. 9 Comparison of Soot versus Crank Angle for optimized and baseline (VCR diesel) 


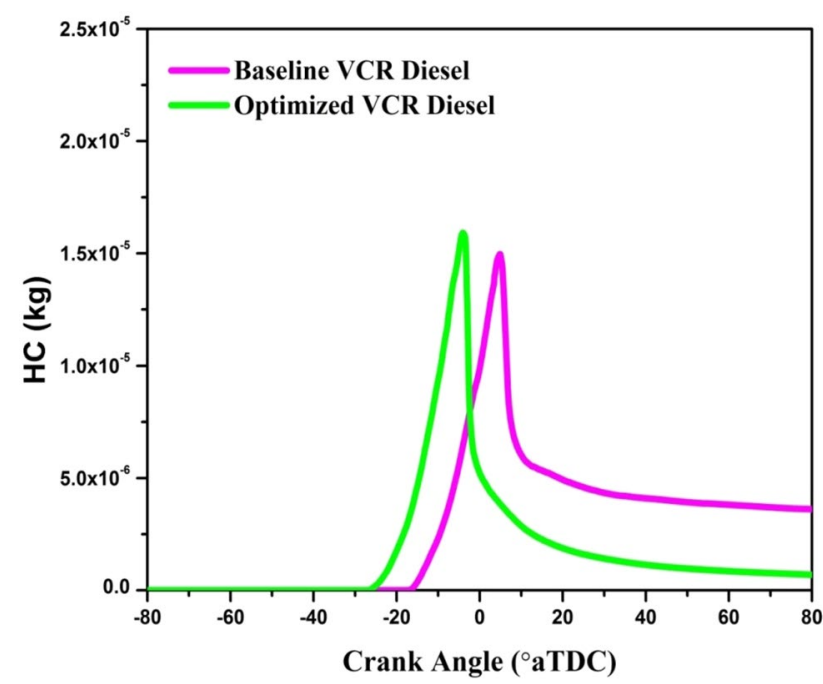

Fig. 10 Comparison of HC versus Crank Angle for baseline and optimized (VCR diesel)

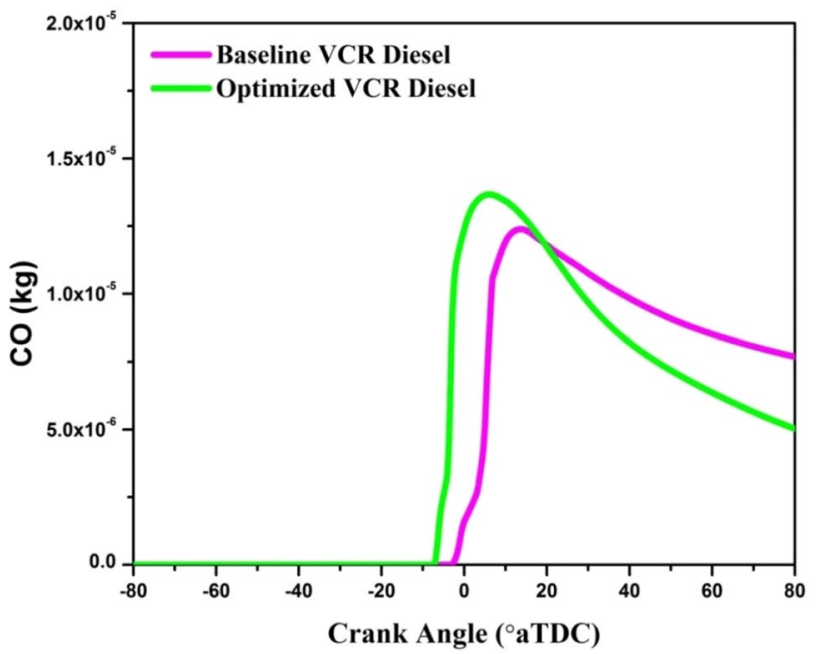

Fig. 11 Comparison of CO versus Crank Angle for baseline and optimized (VCR diesel)
Table 7 Comparison of baseline and optimized cases of VCR diesel engine

\begin{tabular}{llll}
\hline & ISFC (g/kWh) & NOx $(\mathrm{g} / \mathrm{kWh})$ & Soot $(\mathrm{g} / \mathrm{kWh})$ \\
\hline $\begin{array}{l}\text { Baseline case of VCR } \\
\text { diesel }\end{array}$ & 210.25 & 5.29 & 1.18 \\
$\begin{array}{l}\text { Optimized case of VCR } \\
\text { diesel }\end{array}$ & 205.48 & 3.75 & 0.191 \\
\begin{tabular}{l} 
Change w.r.t baseline \\
\hline
\end{tabular} & $\mathbf{2 . 3 7 \% \downarrow}$ & $\mathbf{2 9 . 1 1 \% \downarrow}$ & $\mathbf{8 3 . 8 1 \% \downarrow}$ \\
\hline
\end{tabular}

and NOx decreased by $29.11 \%$ and soot decreased by $83.81 \%$ with respect to the baseline case. The decreased soot is because of the advanced injection and higher injection pressure. The reduced temperature due to presence of EGR favours the NOx reduction.

\subsection{Mixture homogeneity comparison of the baseline and optimized cases}

TFDI (Target Fuel Distribution Index) determines the homogeneity of the mixture [25] and is compared for the baseline and optimized cases at different crank angle instances during the combustion as shown in Fig. 12.The target range of the equivalence ratio for the practical diesel engine applications is from 0.3 to 1.2 [3]. It is observed that the optimized case has more TFDI than the baseline case in all the instances. This is a clear indication of the better homogeneous mixture formation in the optimized case than the baseline case. Better homogeneity was attained due to advanced injection, higher fuel injection pressure and presence of EGR in the optimized case. Better homogeneity favors the lesser soot formation in optimized case. Figure 13 shows the temperature distribution plotted in the target region. It is also observed that the target region has lesser in-cylinder temperatures for optimum configuration than the baseline case which is responsible for lesser NOx. 


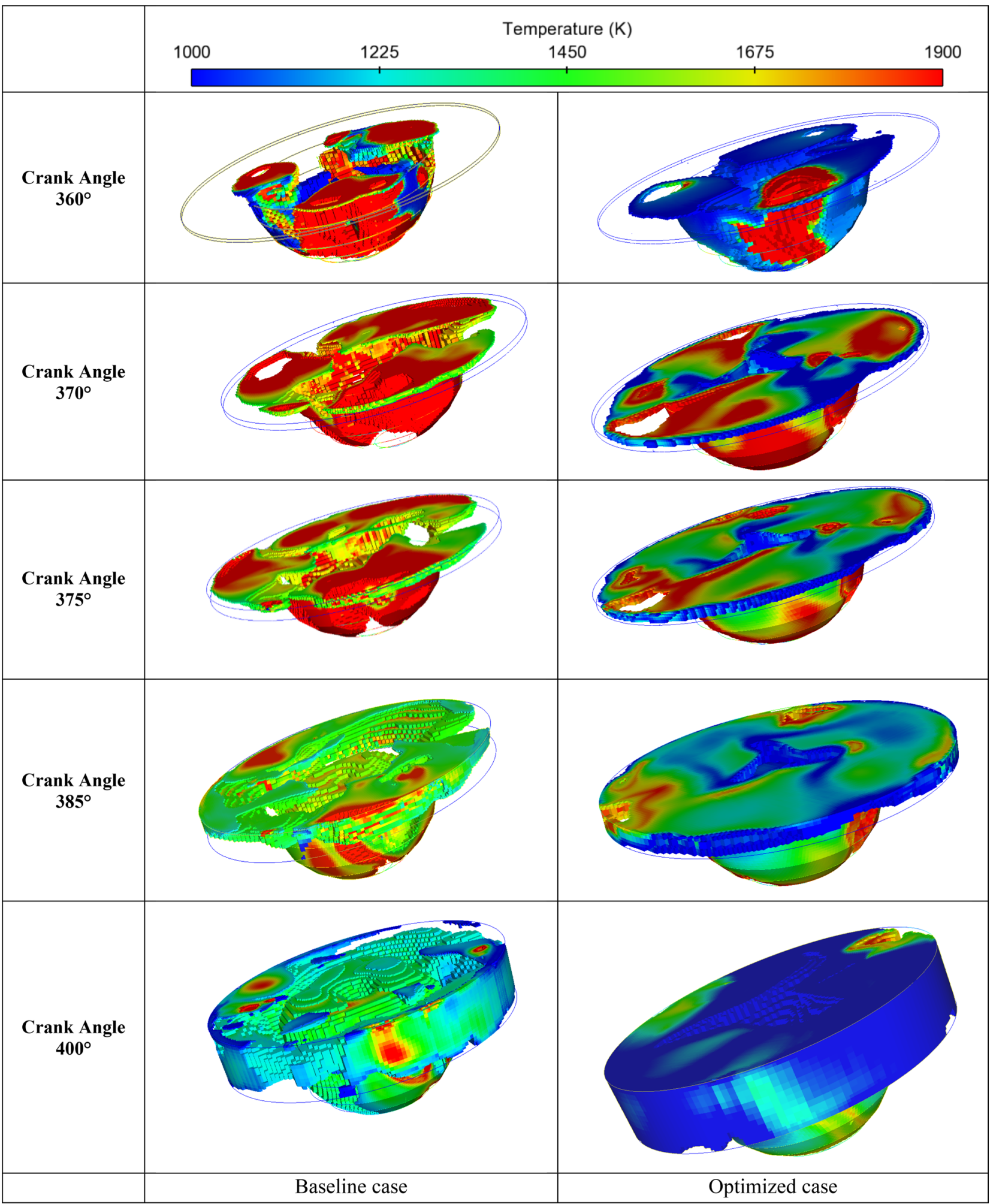

Fig. 12 Equivalence ratio distribution of baseline and optimized cases at different crank angles 


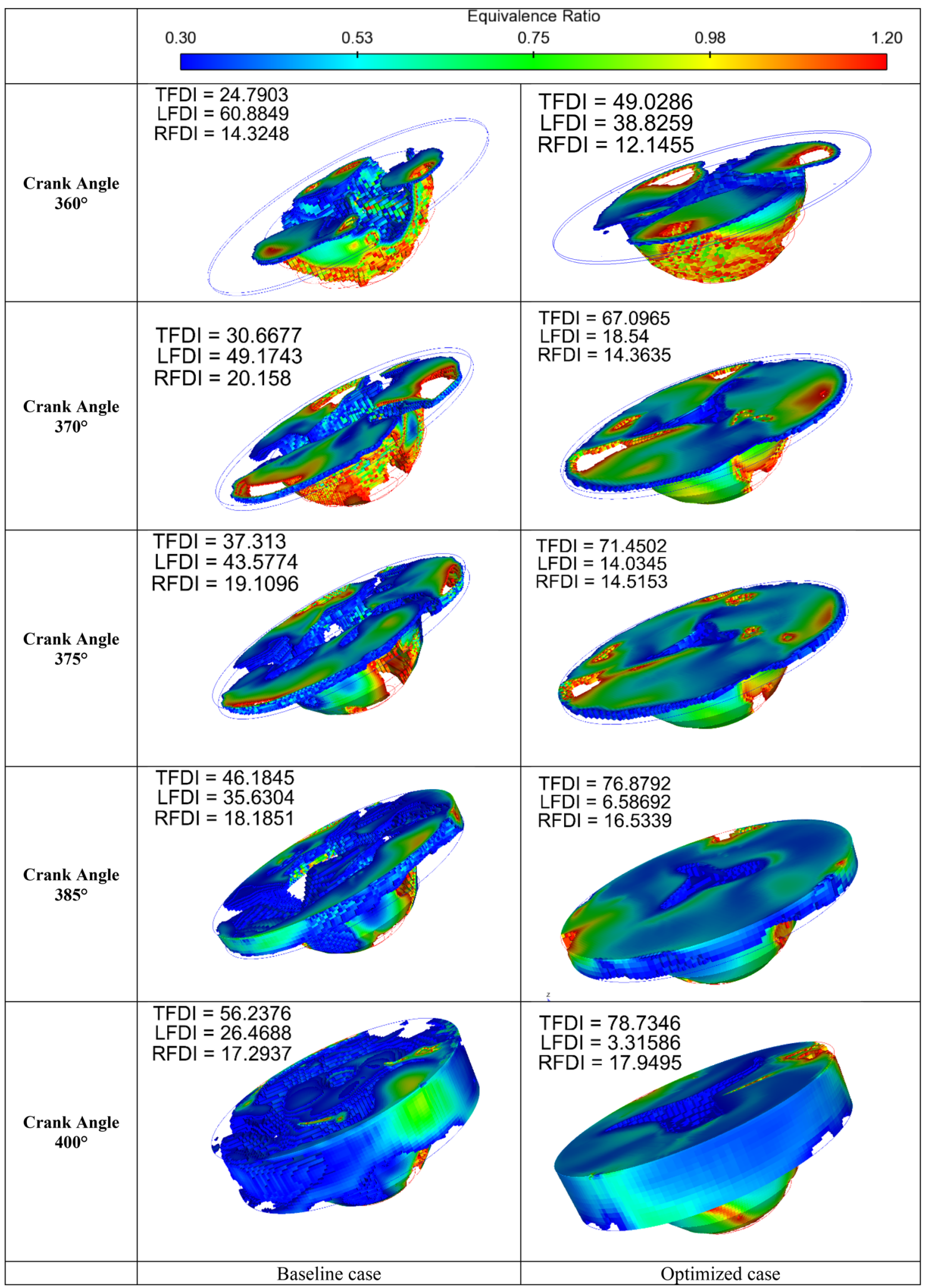

Fig. 13 Temperature distribution of baseline and optimized cases at different crank angles (VCR diesel) 


\section{Conclusions}

The VCR diesel engine was analyzed using DOE based study and optimization has also been done using desirability technique. Start of Injection is the second most influential parameter in view of ISFC. This implies that the $\mathrm{CR}$ and $\mathrm{SO}$ are two potential parameters in deciding the engine performance. However, there is a limit in advancing SOI due to the possibility of negative work. Overall the individual effects play a major role in deciding the ISFC. This means the linear relation with respect to the individual parameters are dominant over the squared and interaction effects. The optimum combination of the VCR diesel was found out to be CR 17.52, SOI $-30.1^{\circ}$ aTDC, FIP 736.06 bar and EGR $28.29 \%$ with a composite desirability of 0.95 . Optimized set of combination was capable of reduced $\mathrm{NOx}$, soot, $\mathrm{HC}$ and $\mathrm{CO}$ emissions as compared to the baseline VCR diesel. ISFC, NOx and soot are reduced by $2.37 \%, 29.11 \%$ and $83.81 \%$ respectively. It was likewise mentioned that the optimized case got higher target fuel distribution index (TFDI) which proves that better homogenous mixture was achieved.

It is crucial to mention that the optimal solutions are only for a particular load and speed other load and speed shall have different optimum conditions. Hence, in future numerical experiments can be carried out to obtain optimal conditions for various loads and speeds. The parametric study may be analyzed further and can be optimized using Genetic Algorithm based optimization techniques such as NSGA II, ARMOGA etc. to obtain Pareto optimal solutions.

Author contributions Prabhakara Rao Ganji: Collected the data from the literature survey, Conceived and design the analysis, Graphical work. Rajesh Khana Raju Vysyaraju: Supervisor 1, Contributed data analysis, Numerical analysis, Optimization. Srinivasa Rao Surapaneni: Supervisor 2, Reference work, Performed the result analysis, Wrote the paper. B Karuna Kumar: Reference work, Performed the result analysis, Proof read the paper.

\section{Declarations}

Conflict of interest The authors declare that they have no conflict of interests.

Ethical approval The authors confirm that the final version of the manuscript has been reviewed, approved, and consented for publication by all author.

Ethical Standards This study was as per the ethical standards approved by the Animal Use Ethics Committee of the University of Oeste Paulista (UNOESTE), Presidente Prudente, São Paulo, Brazil, by Protocol Number 4396.
Open Access This article is licensed under a Creative Commons Attribution 4.0 International License, which permits use, sharing, adaptation, distribution and reproduction in any medium or format, as long as you give appropriate credit to the original author(s) and the source, provide a link to the Creative Commons licence, and indicate if changes were made. The images or other third party material in this article are included in the article's Creative Commons licence, unless indicated otherwise in a credit line to the material. If material is not included in the article's Creative Commons licence and your intended use is not permitted by statutory regulation or exceeds the permitted use, you will need to obtain permission directly from the copyright holder. To view a copy of this licence, visit http://creativecommons. org/licenses/by/4.0/.

\section{References}

1. Agarwal D, Singh SK, Agarwal AK (2011) Effect of exhaust gas recirculation (EGR) on performance, emissions, deposits and durability of a constant speed compression ignition engine. Appl Energy 88:2900-2907. https://doi.org/10.1016/j.apene rgy.2011.01.066

2. Agarwal AK, Srivastava DK, Dhar A et al (2013) Effect of fuel injection timing and pressure on combustion, emissions and performance characteristics of a single cylinder diesel engine. Fuel 111:374-383. https://doi.org/10.1016/j.fuel.2013.03.016

3. Akihama K, Takatori Y, Inagaki K et al (2001) Mechanism of the smokeless rich diesel combustion by reducing temperature. https://doi.org/10.4271/2001-01-0655

4. Bendu H, Murugan S (2014) Homogeneous charge compression ignition $(\mathrm{HCCl})$ combustion: mixture preparation and control strategies in diesel engines. Renew Sustain Energy Rev 38:732746. https://doi.org/10.1016/j.rser.2014.07.019

5. Bhoobathi R (2010) Diesel engine combustion simulation using computational fluid dynamics 01: 17-21

6. Box GE, Draper NR (1987) Empirical model-building and response surfaces. Wiley, New York

7. Derringer G, Suich R (1980) Simultaneous optimization of several response variables. J Qual Technol 12:214-219

8. Dhyani V, Subramanian KA (2019) ScienceDirect Control of backfire and NOx emission reduction in a hydrogen fueled multi-cylinder spark ignition engine using cooled EGR and water injection strategies. Int J Hydrogen Energy 44:6287-6298. https:// doi.org/10.1016/j.ijhydene.2019.01.129

9. Elumalai PV, Balasubramanian D, Parthasarathy M (2021) An experimental study on harmful pollution reduction technique in low heat rejection engine fuelled with blends of pre-heated linseed oil and nano additive. J Clean Prod 283:124617. https:// doi.org/10.1016/j.jclepro.2020.124617

10. Elumalai PV, Dhinesh · J. Jayakar· M. Nambiraj · V. (2021) Effects of antioxidants to reduce the harmful pollutants from diesel engine using preheated palm oil - diesel blend. J Therm Anal Calorim. https://doi.org/10.1007/s10973-021-10652-2

11. Elumalai PV, Parthasarathy $M$, Murugan $M$ et al (2021) Effect of cerium oxide nanoparticles to improve the combustion characteristics of palm oil nano water emulsion using low heat rejection. Int J Green Energy 00:1-15. https://doi.org/10.1080/15435 075.2021 .1904947

12. Esteco (2017) modeFRONTIER User Guide 2017R4

13. Ganji PR, Chintala KP, Raju VRK, Surapaneni SR (2016) Parametric study and optimization using RSM of DI diesel engine for lower emissions. J Brazilian Soc Mech Sci Eng. https://doi.org/10.1007/ s40430-016-0600-0 
14. Jayashankara B, Ganesan V (2010) Effect of fuel injection timing and intake pressure on the performance of a di diesel engine-a parametric study using CFD. Energy Convers Manag 51:18351848. https://doi.org/10.1016/j.enconman.2009.11.006

15. Kashyap CP, Ganji PR, Senthil Kumar M, et al (2015) Numerical analysis of C.I engine to control emissions using exhaust gas regulation and advanced start of injection. Alexandria Eng J. doi https://doi.org/10.1016/j.aej.2016.03.008

16. Kattela SP, Khana R, Vysyaraju R, et al (2018) Effect of n-butanol / diesel blends and piston bowl geometry on combustion and emission characteristics of $\mathrm{Cl}$ engine Hemi spherical Combustion Chamber

17. Kattela SP, Surapanenai RS, Raju V (2019) Parametric optimization of a direct injection - compression ignition engine fuelled with butanol_diesel blend using response surface methodology.pdf. 1-12

18. Kumar S, Kumar ChauhanVarun M (2013) Numerical modeling of compression ignition engine: A review. Renew Sustain Energy Rev 19:517-530. https://doi.org/10.1016/j.rser.2012.11.043

19. Li T, Okabe Y, Izumi H, et al (2013) Dependence of Ultra-High EGR Low Temperature Diesel Combustion on Fuel Properties

20. Min SH, Suh HK, Cha J (2020) Effect of Simulated-EGR ( N 2) on the distribution characteristics of equivalence ratio and the formation of exhaust emissions in a $\mathrm{Cl}$ engine under early injection conditions. Energy 193:116850. https://doi.org/10.1016/j. energy.2019.116850

21. Myers HR, Montgomery CD, Anderson-Cook MC (2016) Response surface methodology: process and product optimization using designed experiments

22. Pandian M, Sivapirakasam SP, Udayakumar M (2011) Investigation on the effect of injection system parameters on performance and emission characteristics of a twin cylinder compression ignition direct injection engine fuelled with pongamia biodiesel - diesel blend using response surface methodology. Appl Energy 88:2663-2676. https://doi.org/10.1016/j.apenergy. 2011.01.069
23. Prasad KS, Rao SS, Raju VRK (2019) Performance and emission characteristics of a DI-Cl engine operated with $n$-butanol/diesel blends. Energy Sources Part A Recover Util Environ Eff. https:// doi.org/10.1080/15567036.2019.1685611

24. Prasad KS, Rao SS, Raju VRK (2021) Effect of compression ratio and fuel injection pressure on the characteristics of a $\mathrm{Cl}$ engine operating with butanol/diesel blends. Alexandria Eng J 60:1183-1197. https://doi.org/10.1016/j.aej.2020.10.042

25. Ramesh N, Mallikarjuna JM (2016) Evaluation of in-cylinder mixture homogeneity in a diesel $\mathrm{HCCl}$ engine-A CFD analysis. Eng Sci Technol Int J 19:917-925. https://doi.org/10.1016/j.jestch. 2015.11.013

26. Reitz YSH-WGRD (2010) Computational Optimization of internal combustion engines. Springer, Berlin

27. Richards KJ, Senecal PK, Pomraning E (2014) CONVERGE (Version 2.3. 0) Manual

28. Sayin C, Gumus M, Canakci M (2012) Effect of fuel injection pressure on the injection, combustion and performance characteristics of a DI diesel engine fueled with canola oil methyl esters-diesel fuel blends. Biomass Bioenerg 46:435-446. https:// doi.org/10.1016/j.biombioe.2012.07.016

29. Shahabuddin $\mathrm{M}$, Liaquat $\mathrm{AM}$, Masjuki HH et al (2013) Ignition delay, combustion and emission characteristics of diesel engine fueled with biodiesel. Renew Sustain Energy Rev. https://doi. org/10.1016/j.rser.2013.01.019

30. Song R, Hu T, Zhou L et al (2007) Effects of compression ratio on the combustion characteristics of a homogeneous charge compression ignition engine. Front Energy Power Eng China 1:463-467. https://doi.org/10.1007/s11708-007-0068-0

31. Yao M, Zheng Z, Liu H (2009) Progress and recent trends in homogeneous charge compression ignition $(\mathrm{HCCl})$ engines. Prog Energy Combust Sci 35:398-437. https://doi.org/10.1016/j. pecs.2009.05.001

Publisher's Note Springer Nature remains neutral with regard to jurisdictional claims in published maps and institutional affiliations. 